\title{
Influence of original microstructure on the transformation behavior and mechanical properties of ultra-high-strength TRIP-aided steel
}

\author{
Hong-xiang Yin ${ }^{1,2)}$, Ai-min Zhao ${ }^{1,2)}$, Zheng-zhi Zhao ${ }^{1,2)}$, Xiao Li $^{1,2)}$, Shuang-jiao ${ }^{1,2)}{ }^{1, H a n-j i a n g ~ H u}{ }^{1,2)}$, \\ and Wei-guang Xia ${ }^{3)}$ \\ 1) Metallurgical Engineering Research Institute, University of Science and Technology Beijing, Beijing 100083, China \\ 2) Beijing Laboratory of Metallic Materials and Processing for Modern Transportation, Beijing 100083, China \\ 3) Key Laboratory for Mechanics in Fluid Solid Coupling Systems, Institute of Mechanics, Chinese Academy of Sciences, Beijing 100190, China \\ (Received: 14 May 2014; revised: 10 October 2014; accepted: 11 October 2014)
}

\begin{abstract}
The transformation behavior and tensile properties of an ultra-high-strength transformation-induced plasticity (TRIP) steel $(0.2 \mathrm{C}-2.0 \mathrm{Si}-1.8 \mathrm{Mn})$ were investigated by different heat treatments for automobile applications. The results show that F-TRIP steel, a traditional TRIP steel containing as-cold-rolled ferrite and pearlite as the original microstructure, consists of equiaxed grains of intercritical ferrite surrounded by discrete particles of M/RA and B. In contrast, M-TRIP steel, a modified TRIP-aided steel with martensite as the original microstructure, containing full martensite as the original microstructure is comprised of lath-shaped grains of ferrite separated by lath-shaped martensite/retained austenite and bainite. Most of the austenite in F-TRIP steel is granular, while the austenite in M-TRIP steel is lath-shaped. The volume fraction of the retained austenite as well as its carbon content is lower in F-TRIP steel than in M-TRIP steel, and austenite grains in M-TRIP steel are much finer than those in F-TRIP steel. Therefore, M-TRIP steel was concluded to have a higher austenite stability, resulting in a lower transformation rate and consequently contributing to a higher elongation compared to F-TRIP steel. Work hardening behavior is also discussed for both types of steel.
\end{abstract}

Keywords: high strength steels; transformation-induced plasticity; phase transformations; mechanical properties; original microstructure; work hardening

\section{Introduction}

The automobile industry is devoted to improving fuel efficiency by using lightweight structural parts in car bodies. The incorporation of advanced high-strength steel (AHSS) in automotive parts leads to improved fuel efficiency. Transformation-induced plasticity (TRIP) steel, one of the AHSSs, contains a metastable retained austenite phase, which is its prominent characteristic. Recently, silicon-containing TRIP steels have garnered considerable interest due to their excellent properties and potential for use in automotive structural components. TRIP steels exhibit an excellent combination of high strength, superior formability, and good crashworthiness. The TRIP effect, which is the transforma- tion of metastable retained austenite into martensite under local stress, can be essentially attributed to the enhanced formability and energy absorption behavior of TRIP steels [1-3]. The stability of retained austenite involves both thermodynamic and mechanical aspects.

Experimental studies have predominantly aimed at quantifying the austenite volume fraction along with its average carbon concentration and determining how the amount of austenite decreases during deformation of the material [4-10]. However, the stability of austenite is strongly influenced by other microstructural factors such as grain size and morphology, the local stress state, the grain orientation, and the nature of the surrounding multiphase matrix [11-15]. Therefore, new detailed microstructural information at the level of the individual grains is required to accurately con- 
trol austenite stability and its transformation behavior into martensite during plastic deformation, which gives rise to an improved combination of ductility and strength in TRIP steels. In this study, two types of TRIP-aided steel were designed: "F-TRIP" steel and "M-TRIP" steel. The former one is a traditional TRIP steel containing as-cold-rolled ferrite and pearlite as the original microstructure, while the latter one is modified TRIP-aided steel with martensite as the original microstructure. The effects of retained austenite stability on the transformation behaviors and mechanical properties of the steels were investigated in detail. In addition, the volume fraction, carbon concentration, grain size, morphology, and distribution of retained austenite were analyzed. The effects of intercritical temperature on the transformation behaviors and mechanical properties of both steels were also examined. The main purpose of this article is to compare the comprehensive mechanical properties of the two steels, i.e., the product of tensile strength and total elongation (TS $\times \mathrm{TEl}$ ), as opposed to the heat treatment process.

\section{Experimental}

The chemical compositions of the investigated steels are listed in Table 1. The investigated steels were prepared using a laboratory vacuum induction melting process. The ingots were homogenized at $1250^{\circ} \mathrm{C}$ for $2 \mathrm{~h}$, forged between

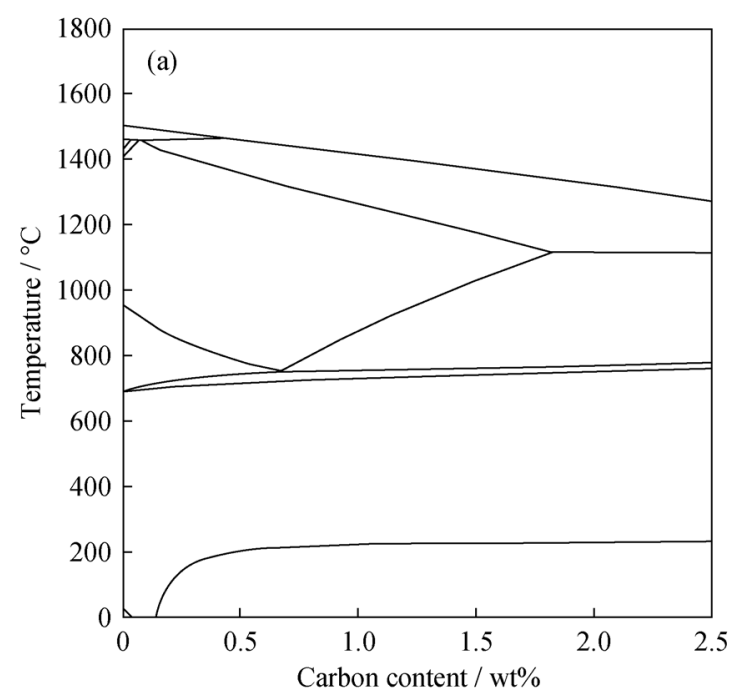

$1200-850^{\circ} \mathrm{C}$ into slabs with dimensions of $40 \mathrm{~mm} \times 90 \mathrm{~mm}$ $\times 90 \mathrm{~mm}$, and finally cooled to room temperature in a furnace. The slabs were reheated to $1200^{\circ} \mathrm{C}$ and hot rolled to a thickness of $4 \mathrm{~mm}$, finished at $850^{\circ} \mathrm{C}$, and then coiled at $600^{\circ} \mathrm{C}$. The hot rolled material was then cold rolled to a final sheet thickness of $1.5 \mathrm{~mm}$ in a cold-rolling mill. The critical temperatures $\mathrm{Ac}_{1}\left(721^{\circ} \mathrm{C}\right)$ and $\mathrm{Ac}_{3}\left(864^{\circ} \mathrm{C}\right)$ of the designed steels were calculated based on the Thermal-Calc software, as shown in Fig. 1 and Table 1. The equilibrium phase diagram and phase fractions in thermodynamic equilibrium were calculated using the Thermo-Calc software, as shown in Fig. 1. The software DICTRA and a mixed-mode kinetic approach including finite interface mobility were applied to simulate the diffusion-controlled phase transformations. The simulations were performed using the thermodynamic database TCFE7 and the mobility database MOB2. The martensite-start temperature $\left(\mathrm{Ms},{ }^{\circ} \mathrm{C}\right)$ of the steel was estimated to be $389^{\circ} \mathrm{C}$ based on the following equation [16], as given in Table 1:

$$
\begin{gathered}
\mathrm{Ms}=539-423 w_{\mathrm{C}}-30.4 w_{\mathrm{Mn}}-7.5 w_{\mathrm{Si}}+ \\
30 w_{\mathrm{Al}}-59.9 w_{\mathrm{P}}
\end{gathered}
$$

\begin{tabular}{|c|c|c|c|c|c|c|c|}
\hline \multicolumn{7}{|c|}{ Chemical composition / wt $\%$} & $\begin{array}{l}\text { Phase transition } \\
\text { temperature } /{ }^{\circ} \mathrm{C} \\
\end{array}$ \\
\hline $\mathrm{C}$ & $\mathrm{Si}$ & $\mathrm{Mn}$ & $\mathrm{P}$ & $\mathrm{S}$ & $\mathrm{Al}$ & $\mathrm{Fe}$ & $\begin{array}{lll}\mathrm{Ac}_{1} & \mathrm{Ac}_{3} & \mathrm{Ms} \\
\end{array}$ \\
\hline 0.19 & 2.07 & 1.79 & 0.011 & 0.008 & 0.011 & Bal. & $\begin{array}{lll}721 & 864 & 389\end{array}$ \\
\hline
\end{tabular}

Table 1. Chemical composition of the investigated steel

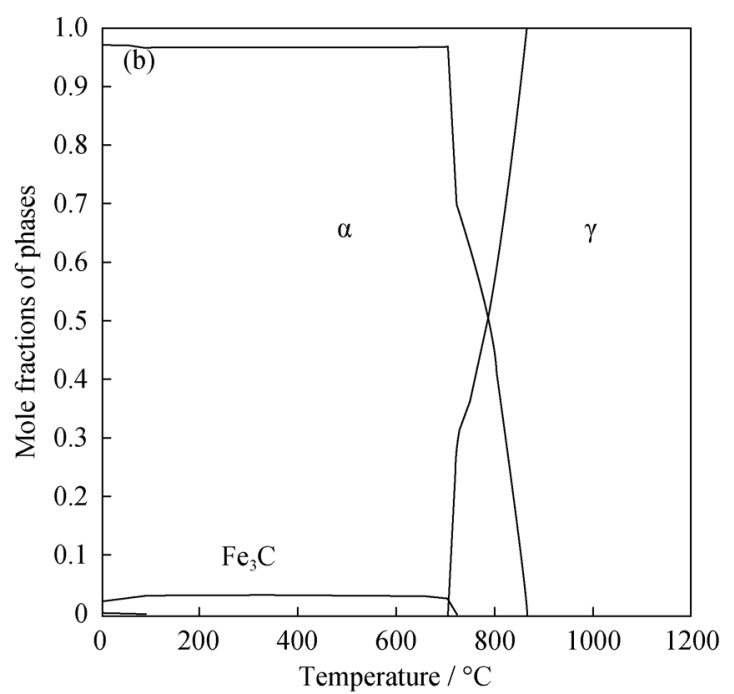

Fig. 1. Simulation diagrams calculated using the Thermo-Calc software: (a) equilibrium phase diagram of Fe-C-Mn-Si steel; (b) equilibrium mole fractions of constituent phases.

where $w_{\mathrm{C}}, w_{\mathrm{Mn}}, w_{\mathrm{Si}}, w_{\mathrm{Al}}$, and $w_{\mathrm{P}}$ are the mass fractions of $\mathrm{C}$, $\mathrm{Mn}, \mathrm{Si}, \mathrm{Al}$, and $\mathrm{P}$ in the steel. The annealing simulations were performed on thin steel sheets of the as-cold-rolled samples with a laboratory CCT-AY-II heat treatment system.
The samples of M-TRIP steel were first heated to the fully austenitic region at $950^{\circ} \mathrm{C}$ and held for $300 \mathrm{~s}$ before quenching at $30^{\circ} \mathrm{C} / \mathrm{s}$ to room temperature. The subsequent process was the same as that for the traditional F-TRIP steel, 
which is called TRIP process. Intercritical annealing was performed on cold-rolled and quenched sheets at 780,800 , 820 , and $840^{\circ} \mathrm{C}$ for $100 \mathrm{~s}$, cooled first at $5^{\circ} \mathrm{C} / \mathrm{s}$ to $680^{\circ} \mathrm{C}$, and then cooled at $45^{\circ} \mathrm{C} / \mathrm{s}$ to the austempering temperature. The samples were held at the austempering temperature $\left(410^{\circ} \mathrm{C}\right)$ for $368 \mathrm{~s}$ and finally cooled to room temperature at a cooling rate of $7^{\circ} \mathrm{C} / \mathrm{s}$ (Fig. 2).

The microstructures were examined using scanning electron microscopy and electron backscatter diffraction (SEM and EBSD, respectively; ZEISS ULTRA 55) along with

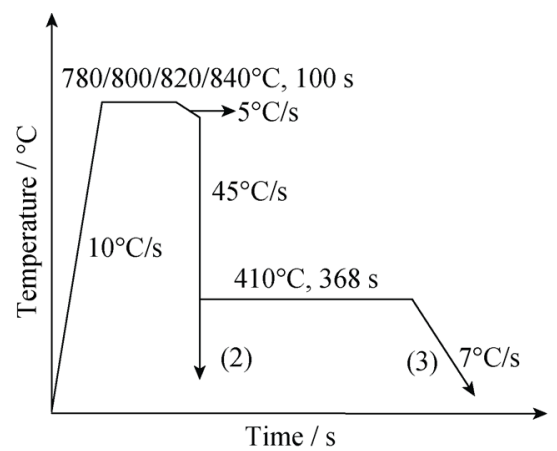

transmission electron microscopy (TEM; JEM2010). The volume fraction of retained austenite was estimated by $\mathrm{X}$-ray diffraction (XRD; Rigaku, DMAX-RB). The samples for SEM were prepared using nital, while the samples for EBSD and XRD measurements were first mechanically ground and polished and then electrolytically etched in a solution of $10 \mathrm{vol} \%$ perchloric acid. The samples for TEM were mechanically ground to a thickness of about $0.04 \mathrm{~mm}$ and then electro-polished in a twin-jet machine in a solution of $5 \mathrm{vol} \%$ perchloric acid and $95 \mathrm{vol} \%$ alcohol at about $-20^{\circ} \mathrm{C}$.

Fig. 2. Schematic of heat treatments for F-TRIP steel (a) and M-TRIP steel (b).

The volume fraction of retained austenite was estimated by XRD using a $\mathrm{Cu}$ target. The calculations were based on the integrated intensities of the $(200)_{\alpha},(211)_{\alpha},(200)_{\gamma},(220)_{\gamma}$, and (311) diffraction peaks. The volume fraction of retained austenite $V_{\gamma}$ was calculated using the following equation:

$V_{\gamma}=\frac{I_{\gamma} K_{\alpha}}{I_{\gamma} K_{\alpha}+I_{\alpha} K_{\gamma}}$

where $I_{\gamma}$ represents the average integrated intensity obtained at the $(200)_{\gamma},(220)_{\gamma}$, and (311) $)_{\gamma}$ diffraction peaks, and $I_{\alpha}$ represents the average integrated intensity obtained at $(200)_{\alpha}$ and (211) $)_{\alpha}$ diffraction peaks; $K_{\alpha}$ and $K_{\gamma}$ are the reflection coefficient of the ferrite and austenite phases, respectively [17].

The retained austenite lattice constant $\left(a_{\gamma}\right)$ was measured based on the (220) $)_{\gamma}$ diffraction peak with a negligible internal stress. The carbon concentration of retained austenite $\left(C_{\gamma}, \mathrm{wt} \%\right)$ was calculated using the following equation [18]:

$C_{\gamma}=\left(a_{\gamma}-3.578\right) / 0.033$

The tensile tests were carried out on a CMT testing machine at $20^{\circ} \mathrm{C}$ at a rate of $2 \mathrm{~mm} / \mathrm{min}$ using specimens with gage lengths of $50 \mathrm{~mm}$, gage widths of $12.5 \mathrm{~mm}$, and thicknesses of $1.5 \mathrm{~mm}$.

\section{Results and discussion}

\subsection{Microstructure}

Fig. 3 shows the original microstructures of the two types

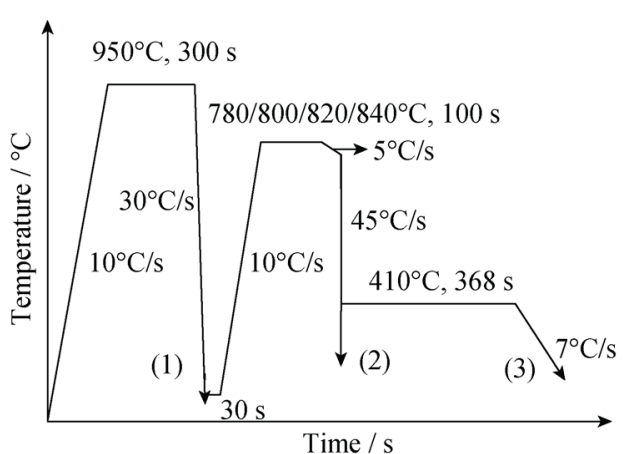

of TRIP-aided steel (F-TRIP steel and M-TRIP steel) before the TRIP process. The original microstructure of F-TRIP steel was as-cold-rolled ferrite (F) and pearlite (P), while that of M-TRIP steel was full martensite. Fig. 4 shows SEM images of the microstructures of F-TRIP and M-TRIP steels at different intercritical annealing temperatures. F-TRIP steel consists of equiaxed grains of intercritical ferrite surrounded by discrete particles of martensite (M)/retained austenite (RA) and bainite (B). In contrast, M-TRIP has lath-shaped grains of ferrite separated by lath-shaped M/RA and B. For both steels, the proportion of ferrite decreases, while intercritical austenite increases as the intercritical annealing temperature is increased. In addition, most of the austenite transforms into bainite in the subsequent austempering process.

In F-TRIP steel, the M/RA islands in the microstructure are primarily located at equiaxed ferrite grain boundaries. Bainite appears as an irregular phase adjacent to the M/RA islands; granular bainite occurs at low annealing temperature, while upper bainite character is prevalent at high annealing temperature (Figs. 4(a)-4(d)). In contrast, in M-TRIP steel, most of the annealing martensite (ferrite) is lath-shaped or lamellar; only a small amount of the lath-shaped annealing martensite merged into block type, and this amount decreased with increasing annealing temperature (Figs. 4(e)-4(h)). Nucleation of intercritical austenite occurred mainly between martensite laths, and the speed of nucleation 

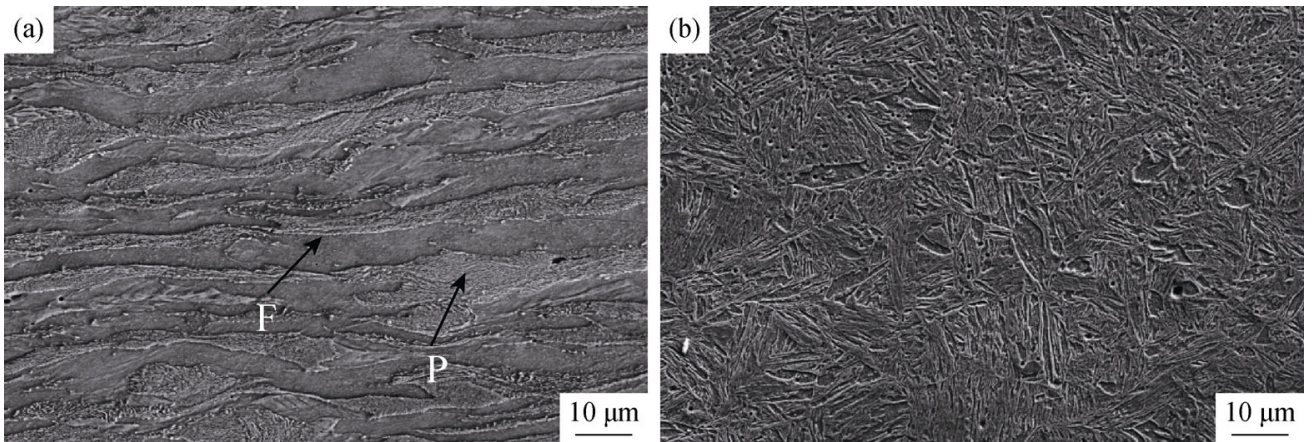

Fig. 3. SEM images showing microstructures of the two types of TRIP-aided steel before the TRIP process: (a) F-TRIP steel; (b) M-TRIP steel.
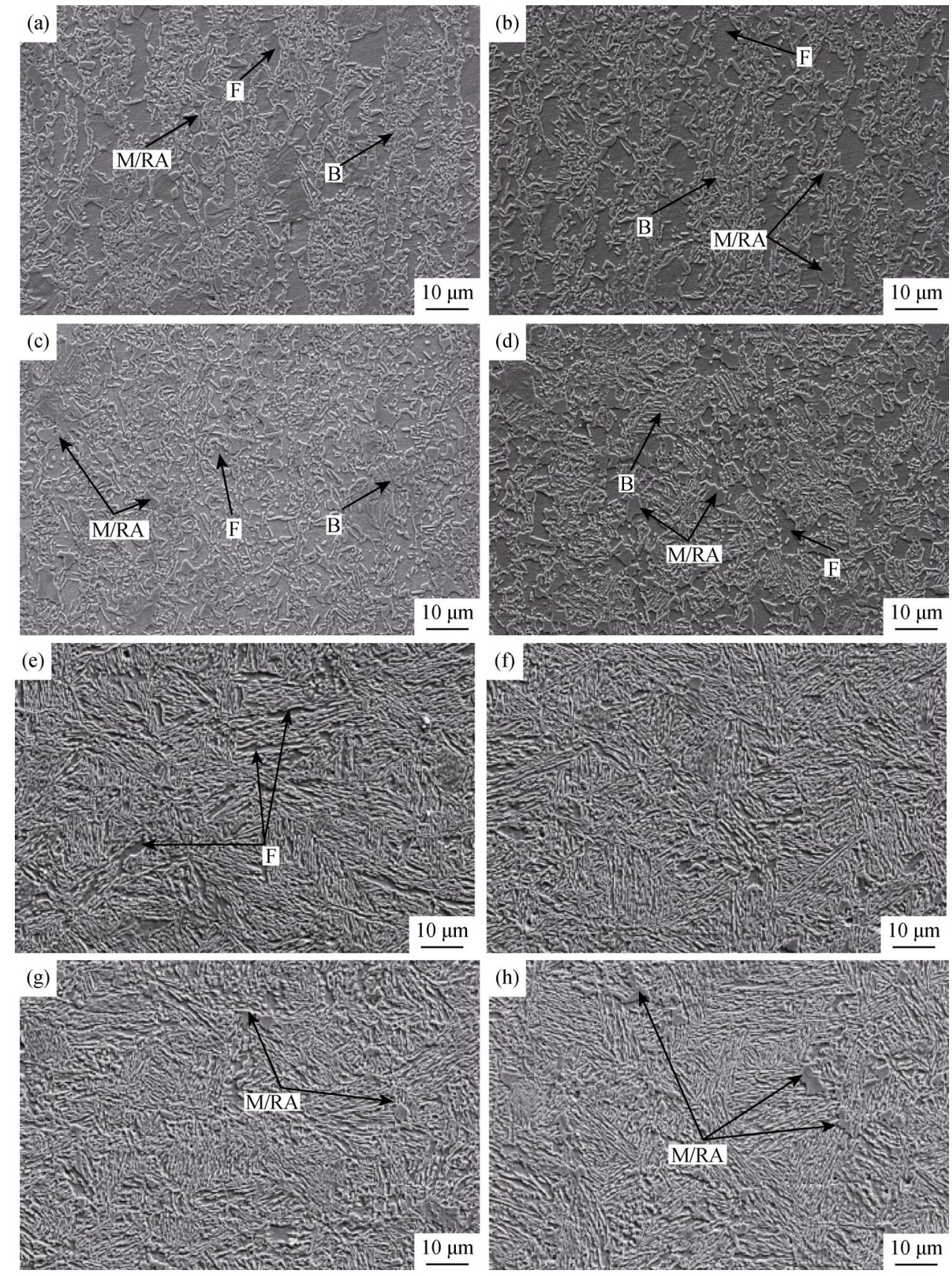

Fig. 4. SEM micrographs of the experimental steels at different annealing temperatures. F-TRIP steel: (a) $780^{\circ} \mathrm{C}$, (b) $800^{\circ} \mathrm{C},(\mathrm{c})$ $820^{\circ} \mathrm{C}$, and (d) $840^{\circ} \mathrm{C}$; M-TRIP steel: (e) $780^{\circ} \mathrm{C}$, (f) $800^{\circ} \mathrm{C},(\mathrm{g}) 820^{\circ} \mathrm{C}$, and (h) $840^{\circ} \mathrm{C}$. 
and growth was closely related to the degree of superheat. At lower intercritical annealing temperatures under a smaller degree of superheat, the slower nucleation and growth was not able to suppress the movement of annealing martensite laths. As a result, adjacent martensite laths merged into blocks, forming the sunken parts indicated by the arrows in Fig. 4(e). With increasing intercritical annealing temperature, the austenite between annealing martensite (ferrite) laths grew quickly and prevented ferrite laths from merging, reducing the amount of blocky ferrite. At higher intercritical annealing temperature, the interlath-retained austenite diffused into the ferrite and merged together, where it transformed into martensite during the subsequent process or was retained at room temperature, as indicated by the bulging

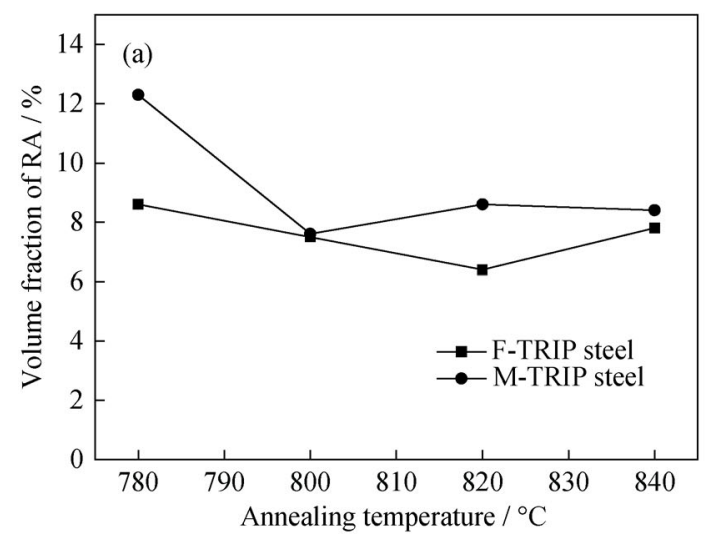

parts in Figs. 4(g)-4(h). Overall, M-TRIP steel exhibits finer microstructure than F-TRIP steel.

\subsection{Austenite characteristics}

The volume fraction of RA and carbon concentration of the RA in F-TRIP steel is lower than those in M-TRIP steel (Fig. 5). The carbon concentration in austenite plays a very important role in austenitic stability, as demonstrated by consistent variation between volume fraction and carbon concentration with different annealing temperatures. The effects of chemical composition, specifically carbon and manganese contents, and temperature can be described by the chemical driving force for martensite transformation through an equation such as the following [13]:

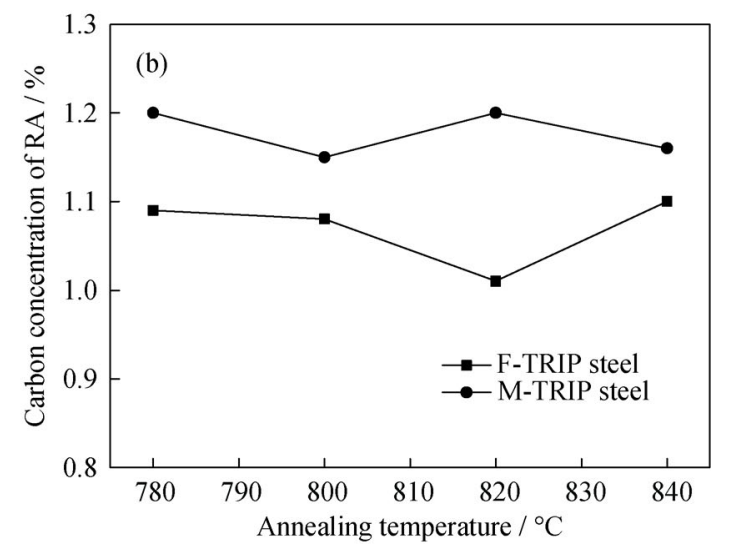

Fig. 5. Volume fraction (a) and carbon concentration (b) of retained austenite as a function of intercritical annealing temperature.

$$
\begin{gathered}
\Delta G^{\mathrm{ch}}=-7381.6+69447 X_{\mathrm{C}}+19296 X_{\mathrm{Mn}}- \\
38776 X_{\mathrm{C}} X_{\mathrm{Mn}}+\left(6.7821-33.45 X_{\mathrm{C}}\right) T
\end{gathered}
$$

where $\Delta G^{\mathrm{ch}}$ is the chemical driving force of martensite transformation, $X_{\mathrm{C}}$ is the mole fraction of carbon, $X_{\mathrm{Mn}}$ is the mole fraction of manganese, and $T$ is the temperature in kelvin. Eq. (1) shows that both carbon and manganese are potent stabilizers of retained austenite.

The stability of retained austenite is also related to morphology. Fig. 6 shows TEM micrographs of F-TRIP steel annealed at $820^{\circ} \mathrm{C}$ and M-TRIP steel annealed at $780^{\circ} \mathrm{C}$. Most of the austenite in F-TRIP steel is present as discrete particles between equiaxed ferrite grains, while the austenite particles in M-TRIP steel are not constrained in such a manner. The retained austenite exists as thin layers between annealing martensite and bainite laths. Harder annealing martensite and bainite help reduce the amount of stress and strain carried by the austenite transformation, which increases the stability of the RA in M-TRIP steel. It is possible that annealing martensite and bainite stabilize RA via stress partitioning. Compared to equiaxed ferrite, the harder an- nealing martensite and bainite might shield neighboring RA from externally-applied stress. The stress partitioning mechanism is based on the theoretical calculation that a hard micro constituent adjacent to RA would reduce the hydrostatic pressure without changing the equivalent stress. Reducing the hydrostatic pressure in turn reduces the mechanical driving force for transformation [13]:

$\frac{\partial \Delta g^{\sigma}}{\partial \bar{\sigma}}=-0.715-0.3206 \frac{\sigma_{h}}{\bar{\sigma}}$

where $\Delta g^{\sigma}$ is the mechanical driving force, $\sigma_{\mathrm{h}}$ is the hydrostatic pressure, and $\bar{\sigma}$ is the equivalent stress. Moreover, the morphology of the retained austenite inside the bainite and annealing martensite are significantly different from those of retained austenite inside equiaxed ferrite, which may also affect how stress is partitioned between the micro constituents.

The stability of retained austenite is also affected by its size. The austenite grains in M-TRIP steel are finer and more discrete than those in F-TRIP steel, which also contributes to the increased austenite stability (Figs. 7 and 8). The effects of retained austenite grain size can be attributed 
to the probability of martensitic nucleation and the energy barrier to the growth of martensite. Finer retained austenite grains contain fewer pre-existing martensite nuclei and therefore a lower probability of transformation. The interfa-

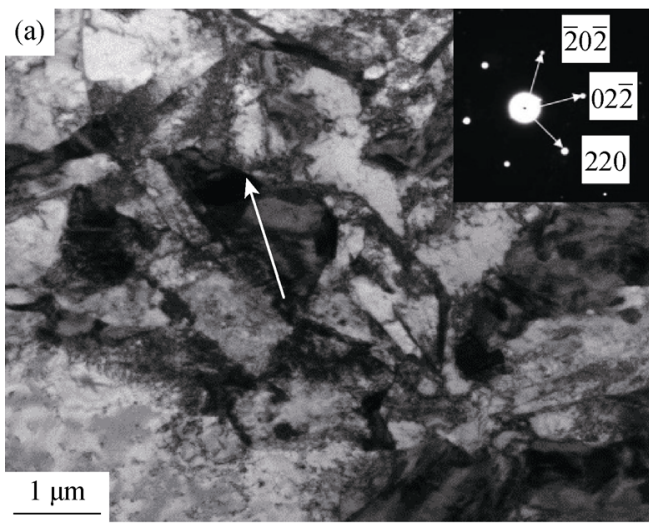

cial energy of the emerging martensite-RA interface also acts as an energy barrier; in smaller retained austenite grains, the molar interfacial energy is larger than that in larger RA grains.

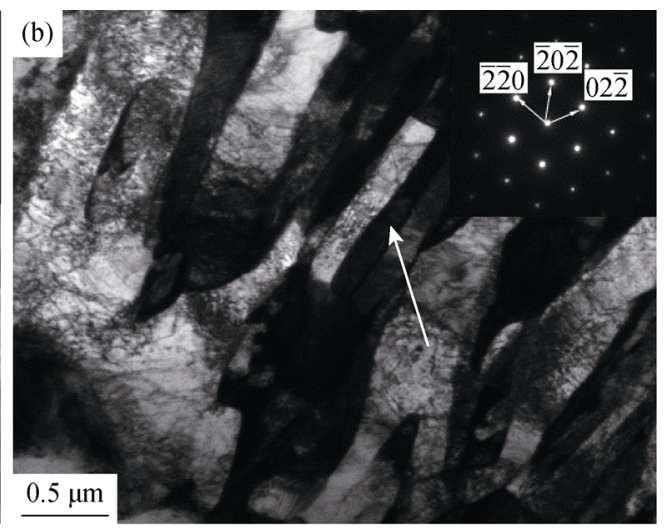

Fig. 6. TEM micrographs of F-TRIP steel annealed at $820^{\circ} \mathrm{C}$ (a) and M-TRIP steel annealed at $780^{\circ} \mathrm{C}(\mathrm{b})$
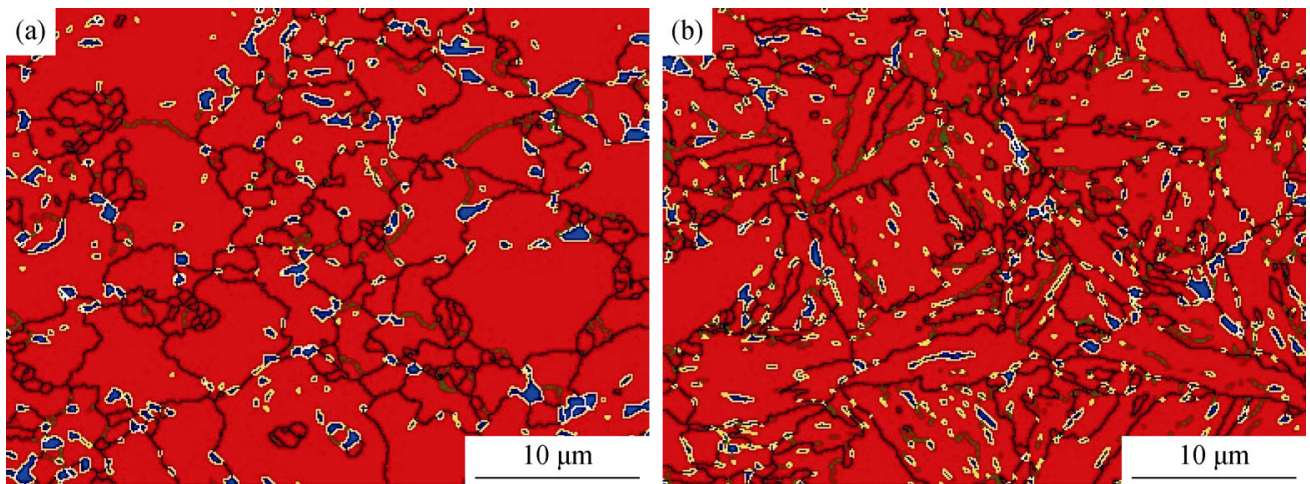

Fig. 7. EBSD micrographs of F-TRIP steel annealed at $820^{\circ} \mathrm{C}$ (a) and M-TRIP steel annealed at $780^{\circ} \mathrm{C}$ (b).

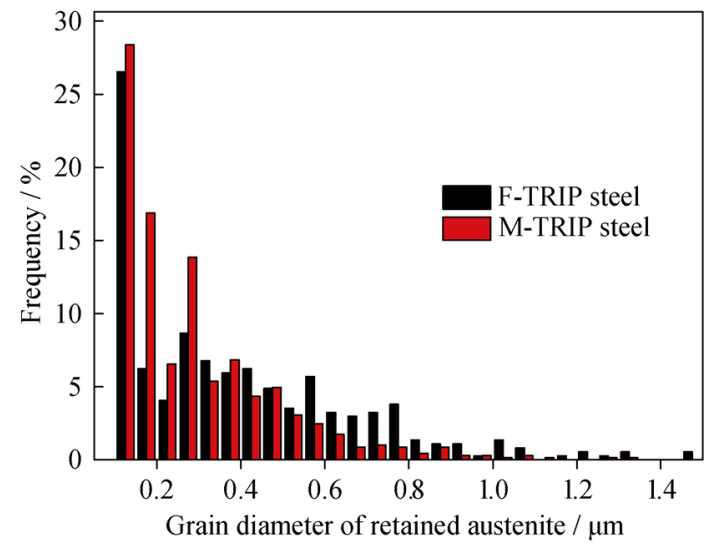

Fig. 8. Grain size distribution of retained austenite in F-TRIP steel annealed at $820^{\circ} \mathrm{C}$ and M-TRIP steel annealed at $780^{\circ} \mathrm{C}$.

Fig. 9 shows variations in $k$ as a function of true strain in F-TRIP and M-TRIP steels; $k$ is the retained austenite stability factor and is defined by the following equation [19]:

$\lg f_{\gamma}=\lg f_{\gamma_{0}}-k \varepsilon$

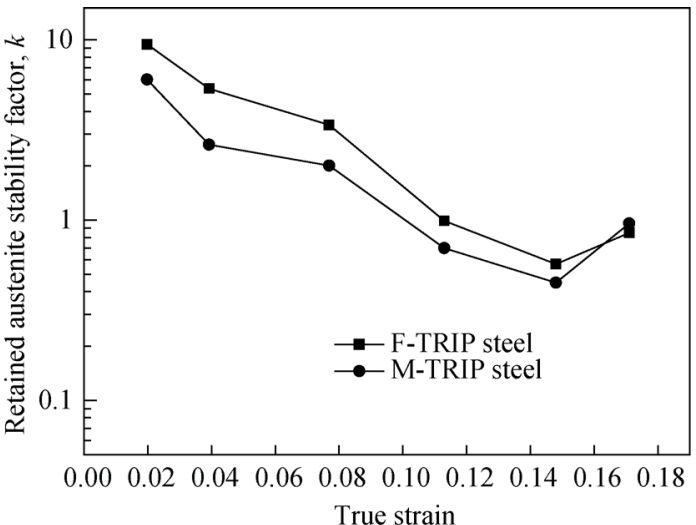

Fig. 9. Variations in $k$ values as a function of true strain in the two types of steel.

where $f_{\gamma_{0}}$ and $f_{\gamma}$ are the volume fractions of retained austenite before and after straining, respectively, and $\varepsilon$ represents plastic tensile strain. The smaller $k$ value indicates more stable austenite. It can be seen that the retained austenite in M-TRIP steel has higher austenitic stability than 
that in F-TRIP steel, which is consistent with the abovementioned results. In two types of steel, $k$ decreases with increasing true strain and increases slightly in the last stage of strain.

\subsection{Mechanical properties}

Fig. 10 illustrates the engineering stress-strain curves of the two types of TRIP-aided steel with different intercritical annealing temperatures. The specimen orientation used in the tensile test is consistent with the rolling direction. Three

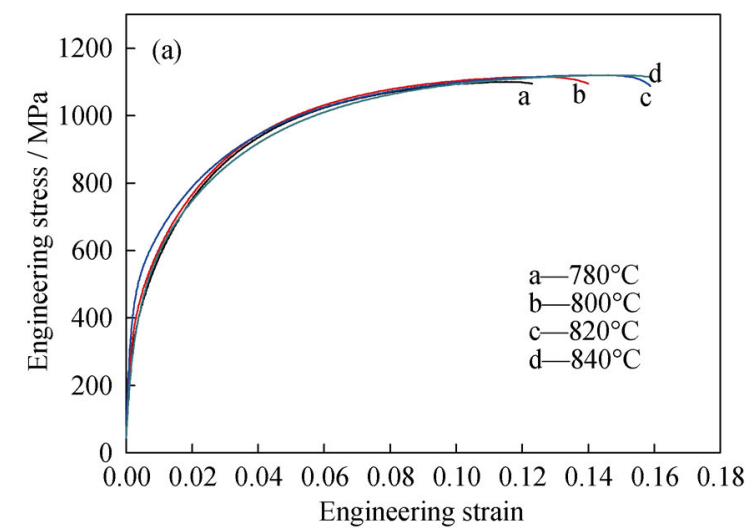

Fig. 10. Engineering stress-strain curves of the two types of steel at different intercritical annealing temperatures: (a) F-TRIP; (b) M-TRIP steel

Fig. 11 shows the variations in the tensile strength (TS), yield strength (YS), and yield ratio (YS/TS), in two types of TRIP-aided steel as a function of intercritical annealing temperature. F-TRIP steel has lower yield strength but a higher tensile strength than M-TRIP steel. It is conceivable that the initial delay in plastic flow of M-TRIP steel causes a modest increase in yield strength. The higher tensile strength of F-TRIP steel can be attributed to the faster transformation rate of retained austenite, as shown in Fig. 9.

F-TRIP steel has a lower yield ratio than M-TRIP steel, as shown in Fig. 11(b). Moreover, as the annealing temperature increased, the tensile strength remained basically unchanged, while the yield strength first increased and then decreases. The TS is attributed to the hard phase bainite and martensite. The martensite was obtained during the cooling process and the tensile deformation process. At a lower annealing temperature, the amount of bainite is less, while the amount of retained austenite is increased; the opposite trend is observed at a higher annealing temperature (Figs. 4 and 5(a)). The yield behaviors of the alloys strongly depend on the grain size of the soft phase ferrite according to the Hall-Petch formula as well as the ferrite volume fraction and the solid solution of carbon in ferrite. At the preliminary annealing temperatures, finer ferrite grains and the reduction

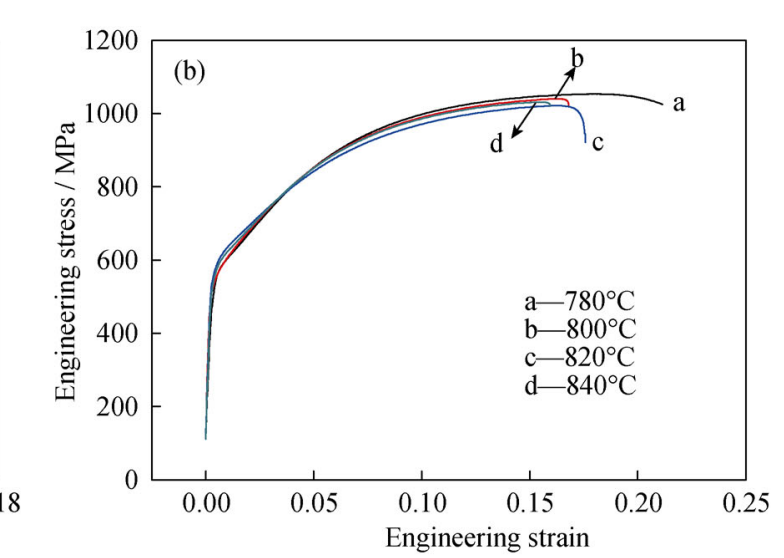

samples were taken for each test, and the averaged value was then obtained. The yield strength, tensile strength, and elongation vary with the intercritical annealing temperature. The true stress-strain curves show that all the investigated samples continuously yielded without a significant yield plateau, similar to the behavior of dual-phase steels and different from the behavior of traditional TRIP steel. Continuous yielding is usually associated with a high mobile dislocation density, which was produced by the martensitic phase transformation. of the ferrite volume fraction are the main factors that determine the increase of yield strength of the steels. At the higher annealing temperature $\left(840^{\circ} \mathrm{C}\right)$, a sharp decrease in solid solution carbon in ferrite leads to a lower yield strength (Fig. 11(a)).

Figs. 12(a) and 12(b) show the total elongation (TEl) and the product of tensile strength and total elongation (TS $\times$ $\mathrm{TEl}$ ) as a function of intercritical annealing temperature, respectively, for both types of steel. M-TRIP steel exhibits higher TEl and TS $\times$ TEl than F-TRIP steel. The TEl and TS $\times$ TEl of F-TRIP steel first increased and then decreased after reaching their maxima at an annealing temperature $820^{\circ} \mathrm{C}$; in contrast, these values for M-TRIP generally decreased from their maximum values at $780^{\circ} \mathrm{C}$. TEl and TS $\times$ $\mathrm{TEl}$ are related to retained austenite characteristics including volume fraction, morphology, grain size, and carbon concentration. A large strength-ductility balance may be achieved by a significant TRIP effect due to the large amount of metastable retained austenite, which gradually transforms into martensite and suppresses a rapid decrease in the strain hardening exponent over a small strain range; this increases uniform elongation, as shown in Fig. 13. F-TRIP has a higher instantaneous $n$ than M-TRIP steel when the strain is less than $2.7 \%$. However, M-TRIP steel 
exhibits a higher instantaneous $n$ when the strain exceeds $2.7 \%$ until necking; it also shows a more slow decrease compared to F-TRIP steel. The observed differences in the work hardening behavior can be explained by comparing the stabilities of retained austenite in the two types of steel. The slower rate of transformation in M-TRIP steel allows for the

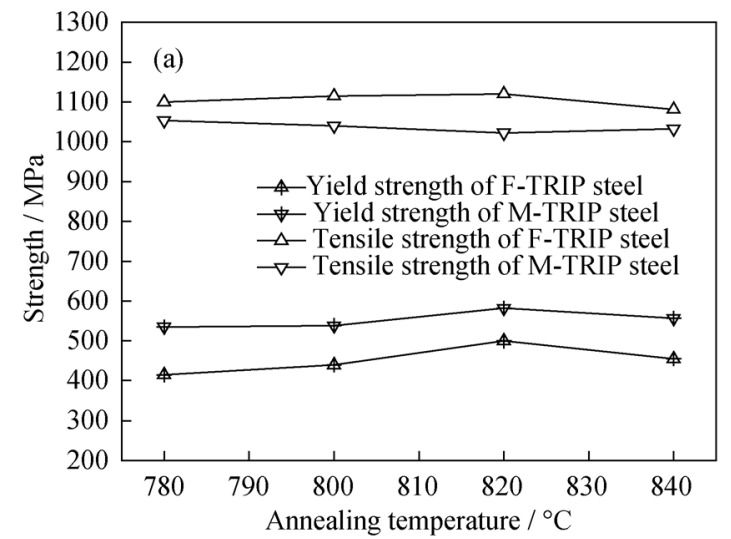

instantaneous $n$ value to be sustained at higher strains compared to F-TRIP steel. That is, at higher strains, some of the austenite phase in M-TRIP steel is still available for transformation, whereas F-TRIP steel has exhausted its TRIP effect. Therefore, retained austenite appears to play a significant role in the work hardening behavior.

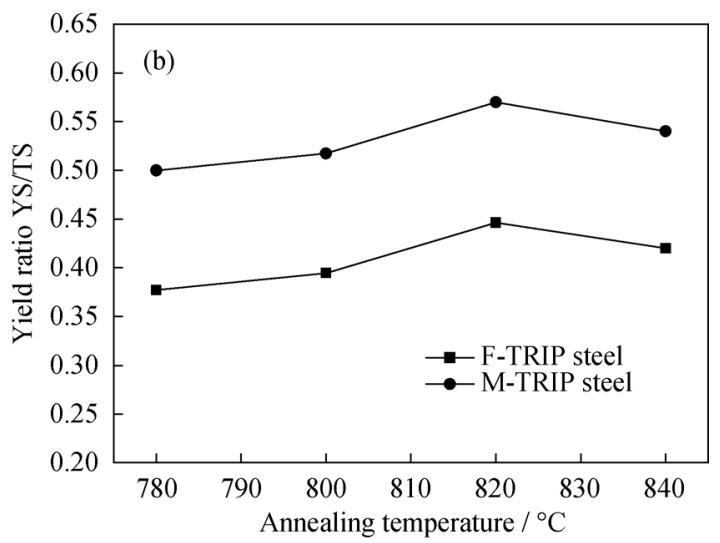

Fig. 11. TS, YS, and YS/TS for both F-TRIP and M-TRIP steels as a function of intercritical annealing temperature.
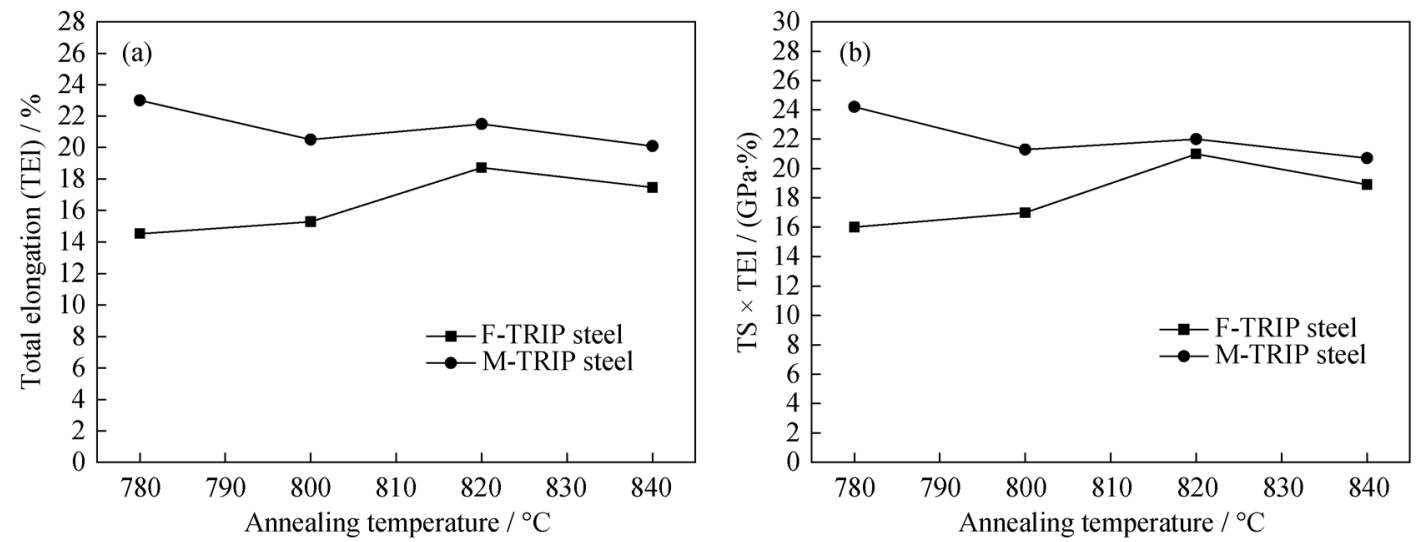

Fig. 12. Values of TEI (a) and TS $\times$ TEI (b) as a function of intercritical annealing temperature for both F-TRIP and M-TRIP steels.

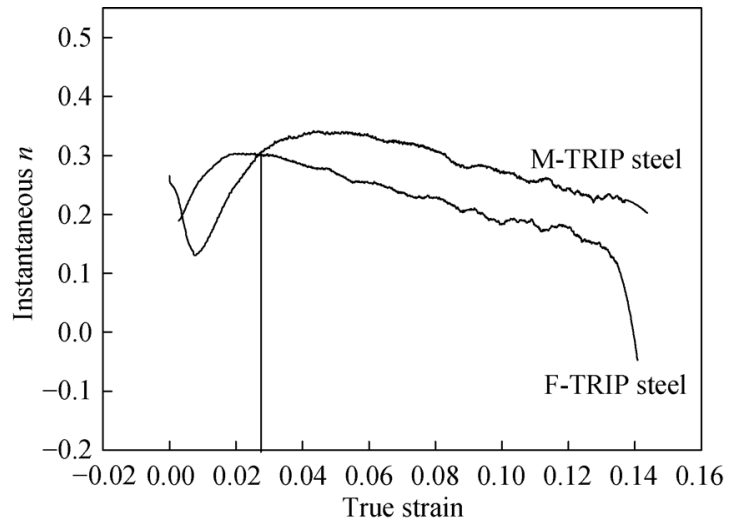

Fig. 13. Work-hardening exponent instantaneous $n$ as a function of true strain for F-TRIP steel annealed at $820^{\circ} \mathrm{C}$ and M-TRIP steel annealed at $780^{\circ} \mathrm{C}$.
Generally speaking, M-TRIP steel has better mechanical properties than F-TRIP steel. Specifically, M-TRIP steel annealed at $780^{\circ} \mathrm{C}$ exhibits the best mechanical properties, which are as follows: tensile strength $=1040 \mathrm{MPa}$; total elongation $=23.0 \%$; product of tensile strength and total elongation $=24.2 \mathrm{GPa} \% \%$. For the F-TRIP steel annealed at $820^{\circ} \mathrm{C}$, tensile strength is $1100 \mathrm{MPa}$, total elongation is $18.7 \%$, and the product of tensile strength and total elongation is $21.0 \mathrm{GPa} \cdot \%$.

\section{Conclusions}

Original microstructure before the TRIP process plays an important role on the final microstructure and mechanical 
properties. A new TRIP-aided steel with annealing martensite as the matrix exhibited a good balance between strength and ductility. These properties mainly depend on the favorable metastable austenite and indicate the potential application of this steel in automotive structural components. The important conclusions can be drawn as follows.

(1) F-TRIP steel containing as-cold-rolled ferrite and pearlite as the original microstructure consists of equiaxed grains of intercritical ferrite surrounded by discrete particles of M/RA and B. In contrast, M-TRIP steel containing full martensite as the original microstructure comprises lath-shaped grains of ferrite separated by lath-shaped M/RA and B.

(2) Most of the austenite in F-TRIP steel is granular, while the austenite in M-TRIP steel is lath-shaped. The volume fraction and carbon concentration of the retained austenite in F-TRIP steel are both lower than those in M-TRIP steel. In addition, the austenite grains in M-TRIP steel are much finer and more discrete than those in F-TRIP steel. The retained austenite in M-TRIP steel is surrounded by bainite, whereas it is surrounded mainly by ferrite in F-TRIP steel. The harder bainite helps reduce the amount of stress and strain carried by the austenite transformation; therefore, the stability of austenite in M-TRIP steel is higher than in F-TRIP steel.

(3) F-TRIP steel has a relatively fast rate of transformation, whereas M-TRIP steel exhibits a slower rate of transformation. Total elongation and work hardening behavior are related to the stability of the retained austenite in the two types of steel. The slower rate of transformation in M-TRIP steel allows the instantaneous $n$ value and elongation to be sustained at higher strains.

(4) Compared to F-TRIP steel, M-TRIP steel has better mechanical properties. Specifically M-TRIP steel annealed at $780^{\circ} \mathrm{C}$ obtains the best mechanical properties, which are a tensile strength of $1040 \mathrm{MPa}$, a total elongation of $23.0 \%$, and a product of tensile strength and total elongation of 24.2 $\mathrm{GPa} \%$. For the F-TRIP steel annealed at $820^{\circ} \mathrm{C}$, tensile strength is $1100 \mathrm{MPa}$, total elongation is $18.7 \%$, and the product of tensile strength and total elongation is 21.0 $\mathrm{GPa} \cdot \%$.

\section{Acknowledgements}

This work is financially supported by the National Natural Science Foundation of China (No. 51271035). The financial support of the Beijing Laboratory of Metallic Materials and Processing for Modern Transportation is also gratefully acknowledged.

\section{References}

[1] V.F. Zackay, E.R. Parker, D. Fahr, and R. Busch, The enhancement of ductility on high-strength steels, Trans. ASM, 60(1967), No. 2, p. 252.

[2] E.V. Pereloma, I.B. Timokhina, and P.D. Hodgson, Microstructure and mechanical properties of thermomechanically processed $\mathrm{C}-\mathrm{Si}-\mathrm{Mn}$ steels, Ironmaking Steelmaking, 28(2001), No. 2 p. 198.

[3] H.B. Ryu, J.G. Speer, and J.P. Wise, Effect of thermomechanical processing on the retained austenite content in a Si-Mn transformation-induced-plasticity steel. Metall. Mater. Trans. A, 33(2002), No. 9, p. 2811.

[4] E. Jimenez-Melero, N.H. van Dijk, L. Zhao, J. Sietsma, S.E. Offerman, J.P. Wright, and S. van der Zwaag, Characterization of individual retained austenite grains and their stability in low-alloyed TRIP steels, Acta Mater., 55(2007), No. 20, p. 6713.

[5] R. Zhu, S. Li, I. Karaman, R. Arroyave, T. Niendorf, and H.J. Maier, Multi-phase microstructure design of a low-alloy TRIP-assisted steel through a combined computational and experimental methodology, Acta Mater., 60(2012), No. 6-7, p. 3022.

[6] B.S. Seong, E.J. Shin, Y.S. Han. C.H. Lee, Y.J. Kima, and S.J. Kim, Effect of retained austenite and solute carbon on the mechanical properties in TRIP steels, Phys. B, 350(2004), No. 1-3, p. E467.

[7] X.D. Wang, B.X. Huang, Y.H. Rong, and L. Wang, Microstructures and stability of retained austenite in TRIP steels, Mater. Sci. Eng. A, 438-440(2006), p. 300.

[8] R. Blondé, E. Jimenez-Melero, L. Zhao, N. Schell, E. Brück, S. van der Zwaag, and N.H. van Dijk, The mechanical stability of retained austenite in low-alloyed TRIP steel under shear loading, Mater. Sci. Eng. A, 594(2014), p. 125.

[9] J. Zrník, O. Muránsky, P. Lukáš, Z. Nový, P. Sittner, and P.Horňak, Retained austenite stability investigation in TRIP steel using neutron diffraction, Mater. Sci. Eng. A, 437(2006), No. 1, p. 114.

[10] R. Blondé, E. Jimenez-Melero, L. Zhao, J.P. Wright, E. Brück, S. van der Zwaag, and N.H. van Dijk, High-energy $\mathrm{X}$-ray diffraction study on the temperature-dependent mechanical stability of retained austenite in low-alloyed TRIP steels, Acta Mater., 60(2012), No. 2, p. 565.

[11] J. Chiang, B. Lawrence, J.D. Boyd, and A.K. Pilkey, Effect of microstructure on retained austenite stability and work hardening of TRIP steels, Mater. Sci. Eng. A, 528(2011), No. 13-14, p. 4516.

[12] Y.F. Shen, Y.D. Liu, X. Sun, Y.D. Wang, L. Zuo, and R.D.K. Misra, Improved ductility of a transformation-induced-plasticity steel by nanoscale austenite lamellae, Mater. Sci. Eng. A, 583(2013), p. 1.

[13] S. Zhang and K.O. Findley, Quantitative assessment of the effects of microstructure on the stability of retained austenite in TRIP steels, Acta Mater., 61(2013), No. 6. p. 1895.

[14] K. Sugimoto, D. Fiji, and N. Yoshikawa, Fatigue strength of 
newly developed high-strength low alloy TRIP-aided steels with good hardenability, Procedia Eng., 2(2010), No. 1, p. 359.

[15] K. Sugimoto, A. Kanda, R. Kikuchi, S. Hashimoto, T. Kashima, and S. Ikeda, Ductility and formability of newly developed high strength low alloy TRIP-aided sheet steels with annealed martensite matrix, ISIJ Int., 42(2002), No. 8, p. 910.

[16] F.G. Caballero, S. Allain, J. Cornide, J.D. Puerta Velásquez, C. Garcia-Mateo, and M.K. Miller, Design of cold rolled and continuous annealed carbide-free bainitic steels, Mater. Des.,
49(2013), p. 667.

[17] H. Maruyama, X-ray measurement of retained austenite volume fraction, J. Jpn. Soc. Heat Treat., (1977), No. 17, p. 198.

[18] D.J. Dyson and B. Holmes, Effect of alloying additions on the lattice parameter of austenite, J. Iron Steel Inst., 208(1970), p. 469.

[19] S.G. Wang, X. Wang, L.X. Hua, Z.W. Liu, and H.L. Zhou, Relationship between retained austenite and strain for $\mathrm{Si}-\mathrm{Mn}$ TRIP steel. J. Univ. Sci. Technol. Beijing, 2(1995), No. 1, p. 7. 